\title{
Chest Wall Cyst
}

National Cancer Institute

\section{Source}

National Cancer Institute. Chest Wall Cyst. NCI Thesaurus. Code C35661.

A cystic lesion in the chest wall. 